\title{
INTRACARDIAC ELECTROPHYSIOLOGICAL STUDY AND ABLATION IN NEPAL
}

\author{
K C Man B, Rajbhandari S, Sharma D, Naik A M
}

\section{ABSTRACT}

Cardiac electrophysiology study (EPS) is one of the most advanced, challenging and a complex branch of invasive cardiology. It involves placement of large sized multipolar catheters in various chambers of the heart. They are used to map and also to ablate the culprit focus of arrhythmia generation. When done by experts, the procedure can be curative. Three electrophysiology workshops were conducted in Shahid Gangalal National Heart Centre. 44 patients underwent the procedure, among which 38 had radiofrequency ablations done and 8 had electrophysiological study. Of the ablated cases all were successful except one had recurrence of tachycardia. Overall success rate was $93 \%$ and no major complications were noted during or after procedure.

\section{Key Words: Electrophysiology, Radiofrequency ablation.}

\section{INTRODUCTION}

Invasive cardiac electrophysiological study (EPS) is one of the most advanced, challenging and a complex branch of modern cardiology. In the early 70 s it was used for diagnostic purposes i.e. in determining the mechanisms of arrhythmia generation. ${ }^{1}$ Then over the next two decades indications and uses of EPS have reached new heights. Intracardiac catheter ablation of atrioventricular junction for control of refractory supraventricular tachycardias were first reported in humans in 1982.,3 Shortcomings of anti - arrhythmic agents ${ }^{4}$ led to the development of radiofrequency catheter ablation and implantable defibrillators which are the milestones in modern cardiology. Radiofrequency energy was introduced in 1987; the energy is obtained from low - energy (10 - 60 volts $)$ and high frequency alternating current $(30 \mathrm{KHz}$ to $300 \mathrm{MHz}$ ). Energy is delivered between the tip of the ablation catheter in contact with endocardium and a large electrode plate positioned over the back. Tissue destruction from radiofrequency energy occurs through heating and desiccation. Local tissue temperature rises up to $60-80^{\circ}$ Celsius causing coagulation necrosis within seconds. ${ }^{6,7,8}$

Electrophysiological study gives valuable information such as the normal and abnormal electrophysiological properties of the conduction system, mechanism of arrhythmia generation, electrical instability of various cardiac chambers and evaluation of antiarrhythmic treatment. Arrhythmia can also be induced and terminated, its anatomical site can be localized and ablated during EPS. Catheter ablation has thus become a frontline therapeutic option for atrioventricular nodal reentry as well as supraventricular tachycardia due to manifest or concealed bypass tracts. With growing experience it is obvious that it will play an increasing role in the treatment of atrial tachycardias, recurrent atrial flutter and idiopathic ventricular tachycardia. Further research is going on to define the role of catheter ablation in Ventricular Tachycardia (VT) associated with coronary artery disease. ${ }^{5}$

* Shahid Gangalal National Heart Centre, Bansbari, Kathmandu, Nepal.

Address for correspondence : $\quad$ Dr. Man Bahadur KC

Shahid Gangalal National Heart Centre, Bansbari, Kathmandu, Nepal.

Email: manbdrkc@yahoo.com 
Mapping catheters are multipolar and are placed in right atrium, across bundle of His, right ventricle, coronary sinus and sometimes in left ventricle. The sizes vary from $4 \mathrm{~F}(1 \mathrm{~F}=$ $0.33 \mathrm{~cm}$ ) to $8 \mathrm{~F}$ and consist of 2 to 20 electrodes with 1 to 10 mm space in between. ${ }^{1}$ Ablation catheter has a tip larger (4 $\mathrm{mm}$ to $6 \mathrm{~mm}$ ) than others. They are introduced via femoral veins, brachial veins and sometimes via internal jugular and subclavian vein. A programmable stimulator which has the ability to pace over a wide range of rates from two sites simultaneously and the ability to introduce a minimum of three extra stimuli coupled to a train of pacing or synchronized to sinus rhythm is required ${ }^{1}$. In addition a recorder which can record intracardiac ECGs in the rate of 10 to $300 \mathrm{~mm} / \mathrm{sec}$ is required. For ablation radiofrequency energy of 300 to 1200 $\mathrm{kHz}$ is applied. ${ }^{1}$

\section{OBJECTIVES}

? To define the mechanisms of arrhythmias and ablate them.

? To diagnose conduction system diseases and plan further management strategies.

? To create a 'cure' for selected patients with supraventricular arrhythmias.

\section{MATERIALS AND METHODS}

Altogether there had been three workshops of EPS till this date in Shahid Gangalal National Heart Centre (SGNHC). The first: $12^{\text {th }}$ October 04 to $15^{\text {th }}$ October 03 , second: 28 February 04 to 2 March 04 and the third: $7^{\text {th }}$ September to $13^{\text {th }}$ September 04 in SGNHC, Kathmandu. Altogether 44 patients were selected for the electrophysiology workshop. Dr. Ajay Madhukar Naik, a consultant electrophysiologist from Ahamadabad India did all the cases of EPS and ablation.

Both groins were shaved and cleaned and draped with sterile towels. Right femoral vein was punctured using Sheldinger's technique and two intravascular sheaths were placed, a single sheath was placed in left femoral vein. In patients with suspected left sided accessory pathway left femoral artery was also punctured and sheath inserted. In two patients right internal jugular vein was used in addition (due to difficulty in placing catheter in coronary sinus). 3 to 4 multipolar catheters were used. Quadripolar catheters were placed in high right atrium, over the bundle of His, right ventricular apex and a decapolar catheter in the coronary sinus which served as a reference electrode. In case of left sided accessory pathway, ablation catheter was inserted via left femoral artery and placed around mitral annulus. Different types of programmed stimulation and non programmed stimulation were applied to induce and terminate tachycardia. Ablation catheter was placed in such a position where a small or absent atrial deflection (A wave) and a large His deflection (V wave) appeared in the intracardiac electrocardiogram. This site corresponds to the slow pathway of atrioventricular nodal reentrant tachycardia (AVNRT) and is the ideal site for delivery of radiofrequency energy thus ablation. Similarly a site where intracardiac A and $\mathrm{V}$ waved merged or are very close to each other corresponds with the location of an accessory pathway. During ablation radiofrequency energy of 35 to 45 watts was applied for 60 to 70 seconds with the temperature ranging from 45 to 60 degree Celsius. The electrophysiology lab system used in the workshop was manufactured by Johnson \& Johnson, USA and consisted of a stimulator, recorder and an ablator.

\section{RESULTS AND DISCUSSION}

Altogether 44 cases were selected for EPS and RF ablations. 38 of them had RF and ablation done and 6 had only EP study. The findings are given in the table below.

After ablation the results were confirmed by attempts to reproduce arrhythmia by programmed and non programmed stimulation and via isoprenaline infusion. Pharmacological atrioventricular block was produced by rapid bolus injection of adenosine to see whether there was conduction via accessory pathway or not. During the procedure 3 patients developed atrial fibrillation, 2 of them was terminated by external cardioversion and one spontaneously reverted to sinus rhythm in the ward. One of the patients had Mahaim bundle which was sub optimally ablated outside Nepal. One patient had hypertrohic cardiomyopathy, one had rheumatic heart disease with moderate mitral regurgitation and one had coronary sinus diverticulum.

Table I : Distribution of Patients who had undergone EPS or EPS and RF ablation

\begin{tabular}{|c|c|c|c|c|c|c|}
\hline \multirow[t]{2}{*}{ Sex } & \multirow[t]{2}{*}{ EPS } & \multicolumn{4}{|c|}{ EPS and Ablation } & \multirow[t]{2}{*}{ Total } \\
\hline & & Typical AVNRT & WPW & Concealed AP & Others & \\
\hline Male & 4 & 3 & 12 & 7 & 0 & 26 \\
\hline Female & 2 & 7 & 8 & 0 & 1 & 18 \\
\hline Total & 6 & 10 & 20 & 7 & $1 *$ & 44 \\
\hline
\end{tabular}

* Low right atrial tachycardia 
Out of the 38 ablated cases two with WPW had reappearance of delta waves after the procedure but are free of symptoms till date. One with typical AVNRT also had foci of ectopic atrial tachycardia which could not be ablated completely and had reappearance of tachycardia the next day. In total the ablations were successful with $93 \%$ success rate. Studies done outside shows the technique has success rates ranging from $85 \%$ to $95 \%$ for accessory pathway ablation ${ }^{9,10,11,12,13,14}$ and $96 \%$ for AVNRT. ${ }^{15}$ No major complications were seen in our 44 cases.

\section{CONCLUSION}

Radiofrequency ablation is the most effective treatment which can be curative when compared to traditional antiarrhythmics. This technique has evolved to the point where it is now recommended as the treatment of choice for symptomatic patients with tachycardia due to accessory pathways and most of the patients with AVNRT. In our study the success rate is comparable to the studies done outside with no major complications. As failure and side effects are the major drawbacks of pharmacological treatment, radiofrequency ablation has come forward as a curative and a rewarding modality of treatment.

\section{REFERENCES}

1. Denise L. Janosik, Antonella Quattromani, Lisa Schiller. Electrophysiologic studies and ablation techniques. Kern MJ ed, The Cardiac Catheterization Handbook $3^{\text {rd }}$ Edition St. Louis, Missouri: Mosby, 1999; 224-227.

2. Scheinman MM, Morady F, Hess DS, et al: Catheter induced ablation of the atrioventricular junction to control refractory supraventricular arrhythmias. JAMA, 1982; 248: 851.

3. Gallagher JJ, Svenson RH, Kassell JH, et al: Catheter technique for closed - chest ablation of the atrioventricular conduction system. N Engl J Med, 1982; 306: 194.

4. The cardiac arrhythmia suppression trial investigators: prel iminary report: Effect of encainide and flecainide onmortality in a randomized trial of arrhythmia suppression after myocardial infarction. N Engl J Med, 1989; 321: 406.
5. Cardiac catheterization, angiography and intervention: Electrophysiologic ablation therapy. Kevin M. Manahan, Mark E Josephson 689: $5^{\text {th }}$ Edition 1995.

6. Huang SK, Graham AR, Lee MA, Ring ME, et al:Comparison of catheter ablation using radiofrequency versus direct energy: Biophysical, Electrophysiologic, and Pathologic Coservations: $J$ Am Coll Cardiol, 1991; 18: 1091.

7. Huang SK, Graham AR, Bharati S, Lee MA, Goman G, Lev M: Short and long term effects of transcatheter ablation of the coronary sinus by radiofrequency energy. Circulation, 1988; 78: 416.

8. Huang SK, Bharati S, Graham AR, et al: Closed chest catheter desiccation of the atrioventricular junction using radiofrequency energy: A new method of catheter ablation. J Am Coll Cardiol, 1987; 9: 349.

9. Jackman WM, Wang XZ, Friday KJ, et al: Catheter ablation of accessory atrioventricular pathways (Wolff - Parkinson White Syndrome) by radiofrequency current. NEngl J Med, $1991 ; 324: 1605$.

10. Lesh MD, Van Hare GF, Schamp DJ, et al: Curative percutaneous catheter ablation using radiofrequency energy for accessory pathways in all locations: Results in 100 consecutive patients. J Am Coll Cardiol, 1992; 19: 1303.

11. Swartz JF, Tracey CM, Fletcher RD: Radiofrequency endocardial catheter ablation of accessory atrioventricular pathway atrial insertion sites. Circulation, 1993; 87: 487.

12. Kay GN, Epstein AE, Dailey SM, Plumg VJ: Role of radiofrequency ablation in the management of supraventricular arrhythmias: Experience in 760 consecutive patients. $J$ Cardiovasc Electrophysiol, 1993; 4: 371.

13. Schluter M, Geiger M, Siebels J, Duckeck W, Kuck KH: Catheter ablations using radiofrequency current to cure symptomatic patients with tachy-arrhythmias related to an accessory atrioventricular pathway. Circulation, 1991 84: 1644.

14. Calkins H, Sousa J, el - Atassi R, et al: Diagnosis and cure of the Wolff - Parkinson - White syndrome of paroxysmal supraventricular tachycardias during single electrophysiological test. N Engl J Med, 1991; 324: 1612.

15. Scheinmann M: Patterns of catheter ablation practice in the United States. Results of NASPE survey. 1994; 17: 873.

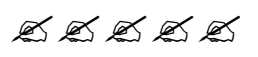

